\title{
A polinização cruzada determina a formação de sementes em frutos de clementina Nules ${ }^{1}$
}

\author{
Fernando Alves de Azevedo², Rogério de Sá Borges ${ }^{3}$, Marco Aurélio Bonin Fávero², \\ Ronald Otto Giorgi Neto ${ }^{2}$, Evandro Henrique Schinor ${ }^{2}$, Marinês Bastianel ${ }^{2}$
}

\begin{abstract}
Cross-pollination determines the seeds formation in Nules clementine fruits

In countries that supply the international market with fresh citrus fruits, there is a great concern about studying the effects of possible crosses between varieties, so that the desirable characteristics, such as the low number of seeds, or even the lack of them, are not altered. Thus, the present study aimed at evaluating the influence of pollination by other citrus varieties in the formation of seeds, in fruits of the Nules clementine seedless variety. Controlled pollinations were performed in 2007 and 2008, with pollen from the sweet orange varieties Pêra, Valência and Natal; Ortanique and Murcott tangors; Nova tangelo; and Ponkan mandarin. The formation of seeds from self-pollination was also evaluated in flowers of Nules clementine. The harvested fruits were evaluated for seeds number, fruit mass $(\mathrm{g})$, transversal and longitudinal diameters $(\mathrm{cm})$. Compatibility was observed for all the varieties evaluated and cross-pollination promoted the formation of seeds. Fruits from the cross-pollination of Nules clementine presented higher size and mass than the ones originated from selfpollination. Isolated flowers of Nules clementine (self-pollinated) produced seedless fruits, suggesting the need of this variety for isolation, in order to obtain seedless fruits.
\end{abstract}

KEY-WORDS: Mandarin; Clemenules; citrus.

\section{INTRODUÇÃO}

No Estado de São Paulo, principal produtor nacional de citros, destacam-se, como as mais cultivadas, as seguintes variedades do grupo das tangerinas e seus híbridos: tangerina Ponkan (Citrus reticulata Blanco) e tangor Murcott [Citrus sinensis (L.) Osbeck x C. reticulata Blanco]. Outras variedades, como a mexerica-do-Rio (C. deliciosa Tenore) e tangerina Cravo, apresentam pouca expressão, com relação à área de plantio (Pio et al. 2005).

\section{RESUMO}

Nos países que abastecem o mercado internacional de frutas cítricas frescas, há uma grande preocupação em se estudar os efeitos de possíveis cruzamentos entre variedades, para que as características desejáveis, como o baixo número de sementes, ou mesmo a ausência delas, não sejam alteradas. Desta forma, o presente trabalho objetivou avaliar a influência da polinização por outras variedades de citros na formação de sementes, em frutos da variedade apirênica clementina Nules. Foram realizadas polinizações controladas em 2007 e 2008, com pólen das variedades de laranja Pêra, Valência e Natal; tangores Ortanique e Murcott; tangelo Nova; e tangerina Ponkan. Também foi avaliada a formação de sementes a partir da autopolinização, em flores de clementina Nules. Os frutos colhidos foram avaliados quanto ao número de sementes, massa de fruto $(\mathrm{g})$, diâmetros transversal e longitudinal $(\mathrm{cm})$. Verificou-se compatibilidade com todas as variedades avaliadas e que a polinização cruzada promoveu a formação de sementes. Frutos de clementina Nules oriundos de polinização cruzada apresentaram maior tamanho e massa que os oriundos da autopolinização. Flores isoladas de clementina Nules (autopolinizadas) produziram frutos sem sementes, evidenciando a necessidade de isolamento, desta cultivar, para a obtenção de frutos apirênicos.

PALAVRAS-CHAVE: Tangerina; Clemenules; citros.

Segundo Gayet (1993), essas variedades não atendem ao padrão de aceitação internacional, para serem consumidas como fruta fresca, pois o mercado valoriza muito as frutas sem sementes. Um exemplo é o tangor Murcott, que é exportado, mas apresenta cerca de 20 sementes por fruto. Pio et al. (2005) ressaltam que, além da ausência de sementes, o consumidor busca frutos cítricos de sabor diferente, tamanho, cor e formas atrativas, fáceis de descascar, com vida de prateleira maior e livre de resíduos químicos. Dentro do grupo das tangerinas,

1. Trabalho recebido em dez./2012 e aceito para publicação em mar./2013 ( ${ }^{\circ}$ registro: PAT 21496).

2. Instituto Agronômico (IAC), Centro APTA Citros Sylvio Moreira, Cordeirópolis, SP, Brasil.

E-mails: fernando@centrodecitricultura.br,marco.favero@syngenta.com,ronald_agri@hotmail.com, evandro@centrodecitricultura.br,mbastianel@centrodecitricultura.br. 
as clementinas (Citrus clementina hort. ex Tanaka) atendem a estes requisitos e são muito cultivadas na região Mediterrânea, principalmente na Espanha, Marrocos e Turquia (FAO 2013).

De maneira geral, as espécies cítricas requerem desenvolvimento de sementes, para frutificação. Quando se autopolinizam, as plantas cítricas formam, aproximadamente, cinco sementes por fruto. Porém, a presença de plantas de outras variedades próximas às de interesse pode aumentar, indesejavelmente, este número (Guardiola 1992).

Azevedo \& Pio (2002), estudando a influência da polinização em tangor Murcott, observaram que, quando flores desta variedade foram polinizadas com pólen das laranjas Valência e Natal, ocorreu incremento no número de sementes, em relação à polinização feita com tangerina Ponkan, laranja Pêra e flores autopolinizadas.

Algumas espécies, entretanto, não necessitam de fertilização, para formarem frutos. Este fenômeno é chamado de partenocarpia, no qual os frutos formados sem polinização não possuem sementes. As variedades de clementina possuem alta taxa de partenocarpia e podem produzir safras comerciais de frutos apirênicos ou sem sementes (Oliveira et al. 2004). Neste caso, seu próprio pólen é incompatível, não promovendo a fertilização dos óvulos. No entanto, caso suas flores sejam polinizadas por pólen oriundo de outras variedades compatíveis, seus frutos poderão apresentar sementes (Donadio et al. 1998).

Com o início do cultivo de variedades de citros sem sementes, torna-se imprescindível o conhecimento da compatibilidade e da taxa de polinização cruzada de cada uma delas com as principais variedades cultivadas no País. Tal conhecimento permitirá o correto planejamento de pomares, evitando o plantio de variedades que possam produzir frutos sem sementes próximo a pomares de variedades compatíveis (Azevedo \& Pio 2001). Desta forma, o presente trabalho objetivou estudar a influência da polinização por outras variedades de citros na formação de sementes, em frutos da variedade apirênica clementina Nules.

\section{MATERIAL E MÉTODOS}

Dois ensaios (ciclos de florescimentos) foram conduzidos no Centro APTA Citros Sylvio Moreira do Instituto Agronômico, em Cordeirópolis (SP), objetivando estudar o efeito de espécies cítricas po- linizadoras na produção de sementes, em frutos da variedade cítrica clemetina Nules (Citrus clementina hort. ex Tanaka).

Os lotes de copas de clementina Nules foram enxertados em citrumelo Swingle (Citrus paradisi Macfad x Poncirus trifoliata L. Raf.) e Poncirus trifoliata, com implantação em 2002, em espaçamento $7 \mathrm{x} 4$.

No primeiro ensaio, realizado em setembro de 2007, por ocasião do florescimento, flores de clementina Nules foram polinizadas com pólen das laranjeiras Pêra, Valência e Natal e das variedades apirênicas tangor Ortanique e tangelo Nova. Flores marcadas no interior da copa (polinização aberta) e de uma segunda floração de clementina Nules também compuseram o ensaio, ainda na florada de 2007 , totalizando sete diferentes tratamentos.

No segundo ensaio, durante a florada de 2008 , ocorrida no mês de setembro, flores de clementina Nules foram polinizadas com pólen de tangor Murcott, tangerina Ponkan e clementina Nules (autopolinização). Neste ano, também foram avaliados tratamentos com polinização aberta, marcando-se flores de clementina Nules do interior e exterior da copa, acondicionadas em sacos de papel, totalizando seis tratamentos.

A polinização controlada e os demais tratamentos (flores internas, externas e ensacamento/ isolamento) foram instalados em 100 flores por tratamento, escolhidas ao acaso, ao redor de cada planta, utilizando-se três repetições (plantas), em delineamento inteiramente casualizado.

Os tratamentos de polinização foram instalados manualmente, após a emasculação das flores (Sócias 1987) com pólen de botões florais que foram coletados ainda fechados, das variedades previamente mencionadas, sendo mantidos em placas de Petri com papel filtro e acondicionados em estufa $\left(30^{\circ} \mathrm{C}\right)$, por 24 horas (Cameron \& Frost 1968). Foram polinizados botões florais fechados, antes da antese, que apresentavam estigmas receptivos, com umidade suficiente para uma polinização efetiva.

$\mathrm{Na}$ época da maturação, aproximadamente aos sete meses após o florescimento e instalação dos ensaios (abril de 2008 e 2009), os frutos oriundos dos diferentes tratamentos foram coletados e avaliou-se a massa dos frutos $(\mathrm{kg})$, obtida por pesagem em balança com capacidade de $15,0 \mathrm{~kg}$ e sensibilidade de 5,0 g; diâmetros longitudinal e transversal $(\mathrm{cm})$, com o uso de régua graduada; e número de sementes, por meio 
de contagem direta, após a abertura dos frutos. As médias obtidas foram submetidas à análise de variância e comparadas entre si, pelo teste Tukey, a 5\%.

\section{RESULTADOS E DISCUSSÃO}

Na avaliação da safra 2007/2008, a influência da polinização cruzada e da autopolinização foram observadas no número de sementes dos frutos de clementina Nules. Os frutos originados da polinização com tangelo Nova e com as laranjas Natal, Valência e Pêra apresentaram maior número de sementes. Por outro lado, um menor número de sementes foi encontrado nos frutos advindos do interior da copa, devido à provável ocorrência de autopolinização (Tabela 1 e Figura 1).

No tratamento envolvendo polinização com tangor Ortanique, verificou-se número de sementes significativamente menor do que o observado na polinização com as laranjas e tangelo Nova, evidenciando que, apesar de haver compatibilidade, a influência do tangor Ortanique no número de sementes de clementina Nules foi menor. Aznar (1999) descreveu influência semelhante dos pólens de tangelo Nova e tangor Ortanique, na Espanha, com maior incremento no número de sementes nos frutos de clementina Nules oriundos de polinização com tangelo Nova. Castañer (2003) salientou que o número médio de sementes

Tabela 1. Altura, diâmetro, massa e número de sementes por fruto de clementina Nules resultantes de cruzamentos com diferentes espécies cítricas (Cordeirópolis, SP, 2008).

\begin{tabular}{|c|c|c|c|c|}
\hline \multirow{2}{*}{ Tratamentos } & Altura & Diâmetro & Massa & Sementes fruto ${ }^{-1}$ \\
\hline & \multicolumn{2}{|c|}{$\mathrm{cm}$} & $\mathrm{kg}$ & $\mathrm{n}^{\mathrm{o}}$ \\
\hline Polinização com tangelo Nova & $7,41 \mathrm{a}$ & $8,06 \mathrm{a}$ & $0,21 \mathrm{a}$ & $29,85 \mathrm{a}$ \\
\hline Polinização com laranja Natal & $7,23 \mathrm{a}$ & $8,05 \mathrm{a}$ & $0,20 \mathrm{ab}$ & $22,90 \mathrm{ab}$ \\
\hline Polinização com laranja Valência & $6,88 \mathrm{a}$ & $7,82 \mathrm{ab}$ & $0,19 \mathrm{abc}$ & $20,86 \mathrm{bc}$ \\
\hline Polinização com laranja Pêra & $6,69 \mathrm{a}$ & $7,18 \mathrm{~b}$ & $0,16 \mathrm{c}$ & $16,51 \mathrm{bc}$ \\
\hline Polinização com tangor Ortanique & $6,64 \mathrm{a}$ & $7,48 \mathrm{ab}$ & $0,17 \mathrm{bc}$ & $12,60 \mathrm{~cd}$ \\
\hline Frutos $2^{\mathrm{a}}$ florada de Nules & $5,26 \mathrm{~b}$ & $5,69 \mathrm{c}$ & $0,09 \mathrm{~d}$ & $7,78 \mathrm{~cd}$ \\
\hline Frutos do interior da copa & $5,72 \mathrm{~b}$ & $6,33 \mathrm{c}$ & $0,12 \mathrm{~d}$ & $4,22 \mathrm{~d}$ \\
\hline C.V. $(\%)$ & 4,12 & 1,74 & 1,22 & 18,83 \\
\hline
\end{tabular}

Médias seguidas da mesma letra, na coluna, não diferem entre si, pelo teste Tukey, a $5 \%$.

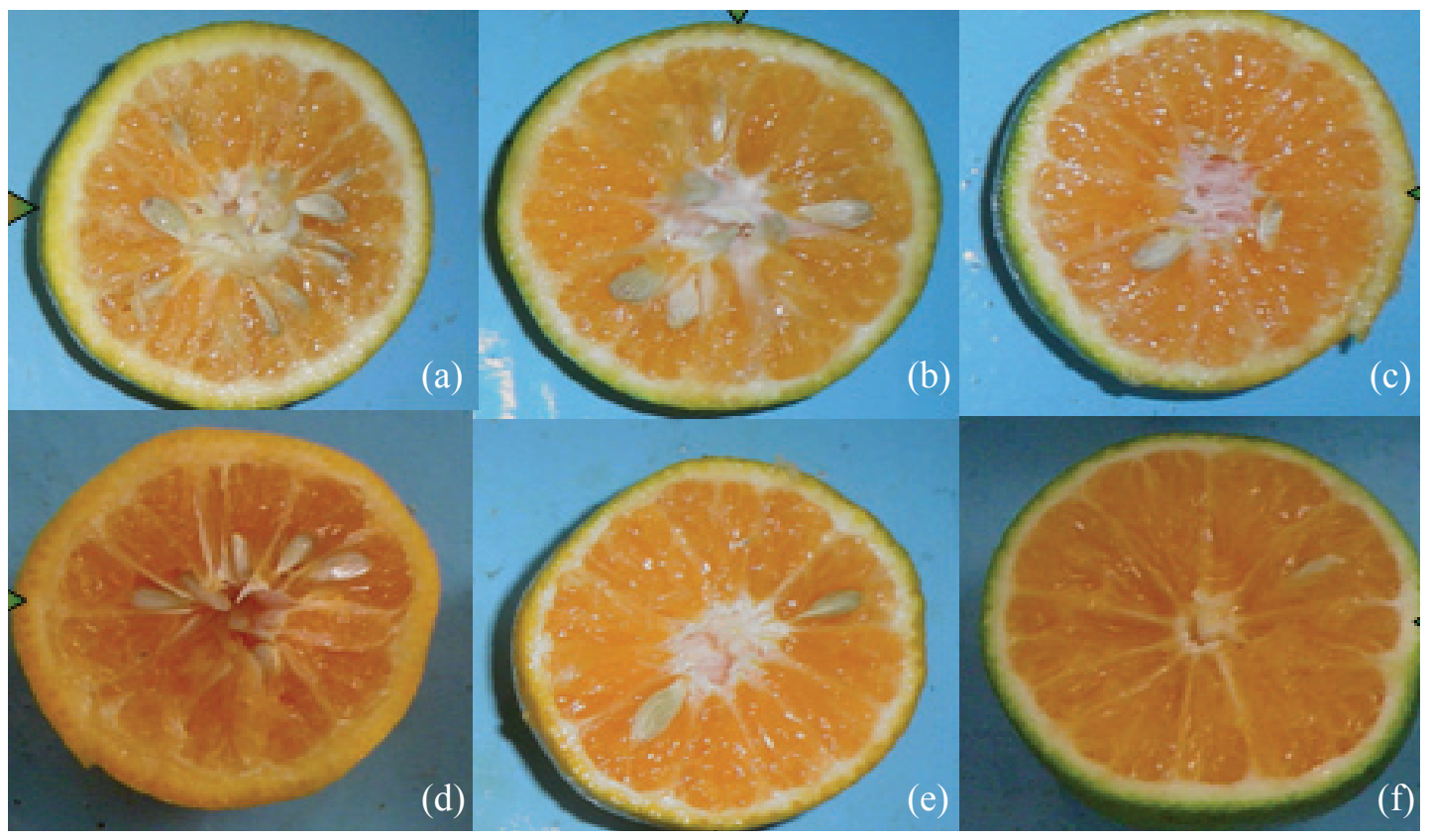

Figura 1. Corte transversal de frutos de clementina Nules oriundos de cruzamentos com tangelo Nova (a); laranjas doces Natal (b), Pêra (c) e Valência (d); tangor Ortanique (e); e de frutos internos da copa (f) (Cordeirópolis, SP, 2008). 
produzidas por fruto de citros varia em função do grau de viabilidade dos gametas e da compatibilidade entre as variedades.

Para o ensaio da safra 2008/2009, todos os frutos advindos das flores isoladas e ensacadas (autopolinizadas) foram apirênicos, o que não ocorreu com os dos demais tratamentos, ressaltando a necessidade do cultivo isolado desta variedade, quando se procura a produção de frutos sem sementes, com qualidade (Tabela 2 e Figura 2). Aznar (1999) enfatizou que a clementina Nules não tem sementes, porém, pode apresentá-las, caso seja cultivada próxima a variedades compatíveis.
O maior número de sementes foi encontrado nos frutos polinizados com tangerina Ponkan e tangor Murcott, o que comprova que há alta compatibilidade com estas variedades. Os frutos localizados na parte externa da copa de clementina Nules apresentaram reduzido número de sementes, uma vez que estas plantas encontravam-se circundadas por variedades de tangerinas como tangelo Nova e tangor Ortanique e de laranjas Valência, Pêra e Salustiana, porém, o florescimento não ocorreu simultaneamente, nestes materiais.

Quando comparados aos frutos advindos da polinização com tangerina Ponkan e tangor

Tabela 2. Altura, diâmetro, massa e número de sementes por fruto de clementina Nules resultantes de cruzamentos com diferentes espécies cítricas (Cordeirópolis, SP, 2009).

\begin{tabular}{lcccr}
\hline \multicolumn{1}{c}{ Tratamentos } & Altura & Diâmetro & Massa & \multicolumn{2}{c}{ Sementes fruto $^{-1}$} \\
\cline { 2 - 5 } & & & $\mathrm{kg}$ & $\mathrm{n}^{\mathrm{0}}$ \\
\hline Polinização com tangor Murcott & $6,49 \mathrm{a}$ & $7,57 \mathrm{a}$ & $0,18 \mathrm{a}$ & $30,58 \mathrm{a}$ \\
Polinização com tangerina Ponkan & $6,48 \mathrm{a}$ & $7,35 \mathrm{a}$ & $0,17 \mathrm{a}$ & $21,15 \mathrm{~b}$ \\
Frutos externos & $5,50 \mathrm{~b}$ & $6,00 \mathrm{~b}$ & $0,10 \mathrm{~b}$ & $1,50 \mathrm{c}$ \\
Frutos internos & $4,73 \mathrm{c}$ & $5,08 \mathrm{c}$ & $0,06 \mathrm{c}$ & $0,58 \mathrm{c}$ \\
Isolamento de flores (ensacamento) & $4,06 \mathrm{~d}$ & $4,50 \mathrm{~d}$ & $0,05 \mathrm{c}$ & $0,00 \mathrm{c}$ \\
\hline C.V. (\%) & 4,88 & 3,60 & 6,04 & 14,75 \\
\hline
\end{tabular}

Médias seguidas da mesma letra, na coluna, não diferem entre si, pelo teste Tukey, a $5 \%$.

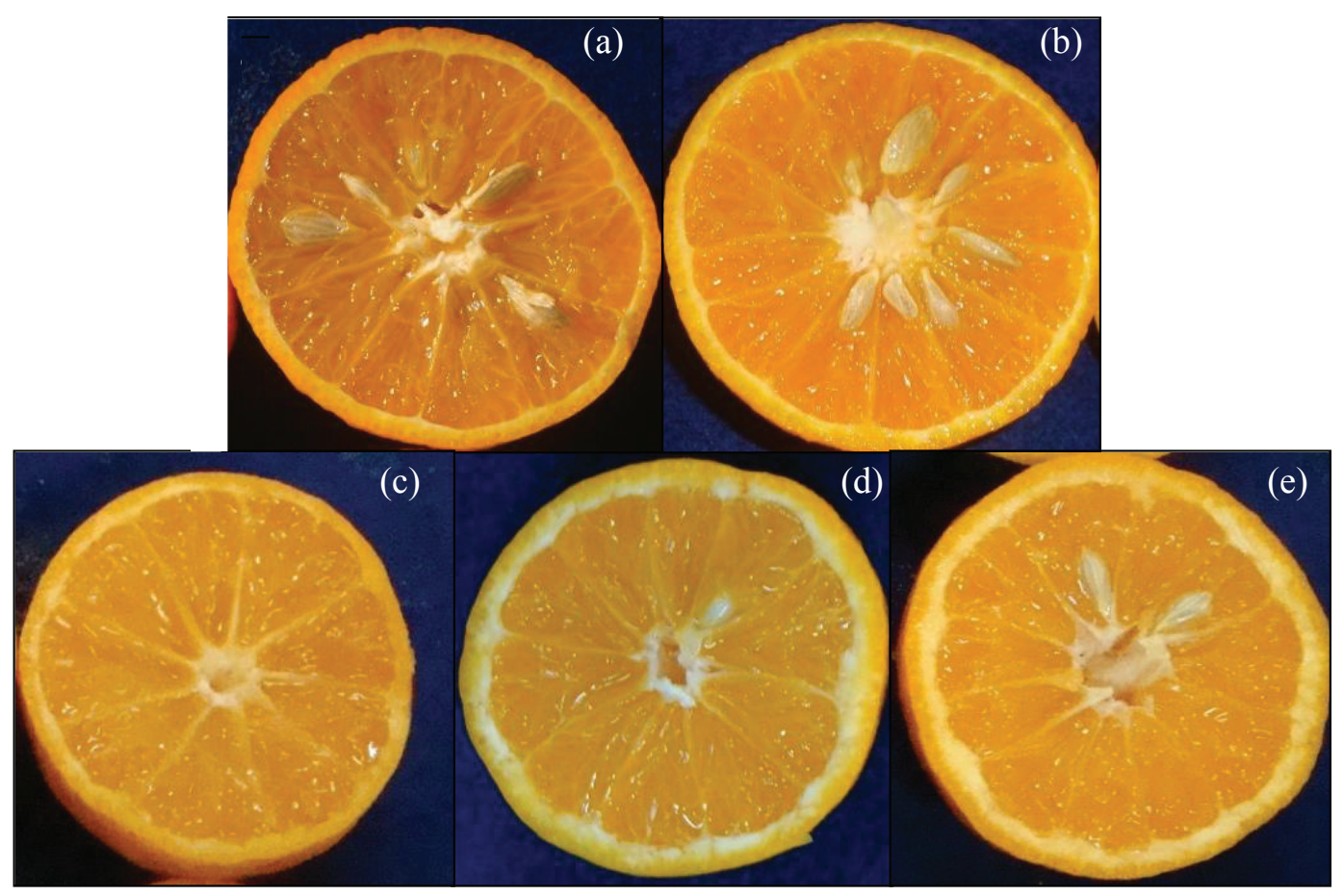

Figura 2. Corte transversal de frutos de clementina Nules oriundos de cruzamentos com tangerina Ponkan (a), tangor Murcott (b), frutos de flores isoladas (c), flores internas (d) e externas na copa (e) (Cordeirópolis, SP, 2009). 
Murcott, os frutos da parte externa da copa apresentaram menor número de sementes, reforçando a hipótese de uma possível polinização cruzada em baixa intensidade. Ferraro et al. (2006) evidenciaram a influência de diferentes pólens (tangerina e laranja) no número de sementes de tangelo Nova, variedade também considerada apirênica, quando autopolinizada.

As flores emasculadas e polinizadas com pólen de clementina Nules não produziram frutos, por isto, não foram apresentadas informações sobre este tratamento, na Tabela 2. Segundo Ben-Cheikh et al. (1997), a eliminação dos estames reduz bastante os níveis de endógenos de giberelina e pode provocar abscisão acentuada dos ovários. Estes autores observaram que a emasculação de flores de laranja Pineapple reduziu os níveis de giberelina a ponto de provocar abscisão de $100 \%$, em seus ovários.

Puchades (2002) avaliou a polinização feita com pólen de clementina Nules, em flores de tangerina Fortune, e verificou que as percentagens de flores que não abortaram foram superiores nas flores que receberam polinização cruzada $(53 \%$ e $80 \%)$, seguida por autopolinização manual $(20 \%$ e $8 \%)$ e flores emasculadas $(0,5 \%$ e $1 \%)$. Estas observações corroboram os resultados obtidos neste estudo.

Nos dois anos de avaliação, verificou-se que os frutos com menor número de sementes foram os de menores dimensões e massa (Tabelas 1 e 2), evidenciando haver uma correlação entre estas características, também relatada por Mischan \& Salibe (1979).

Os resultados observados sugerem que os plantios de clementina Nules, no Brasil, devem distanciar-se de variedades polinizadoras, caso se queira produzir frutos apirênicos e explorar esta importante vantagem comercial.

\section{CONCLUSÕES}

1. Flores de clementina Nules são compatíveis e podem ser fertilizadas pelas variedades tangelo Nova, tangor Ortanique e Murcott, tangerina Ponkan e laranjas Pêra, Natal e Valência, promovendo a formação de frutos com sementes.

2. A polinização cruzada com outras variedades compatíveis, além do número de sementes, aumentou o tamanho e massa dos frutos de clementina Nules.

3. Flores de clementina Nules isoladas originaram frutos partenocárpicos e sem sementes.

\section{REFERÊNCIAS}

AZEVEDO, F. A.; PIO, R. M. Influência da polinização sobre o número de sementes do tangor 'Murcote'. Revista Brasileira de Fruticultura, Jaboticabal, v. 24, n. 2, p. 468471, 2002.

AZEVEDO, F. A.; PIO, R. M. O papel da polinização na citricultura. Citricultura Atual, Cordeirópolis, v. 4, n. 23, p. 4-5, 2001.

AZNAR, J. S. Reconocimiento de variedades de cítricos en campo. Valencia: Generalitat Valenciana, 1999.

BEN-CHEIKH, W. et al. Pollination increases gibberellins levels in developing ovaries of ceded varieties of citrus. Plant Physiology, Waterbury, v. 114, n. 1, p. 557-564, 1997.

CAMERON, J. W.; FROST, H. B. Genetics, breeding and nucellar embriony. In: REUTHER, W. et al. (Eds.). The citrus industry. Berkeley: University of California, 1968. p. 359-360.

CASTAÑER, M. A. Producción de agrios. 3. ed. Madrid: Mundi Prensa, 2003.

DONADIO, L. C. et al. Tangerinas ou mandarinas? Jaboticabal: Funep, 1998. (Boletim citrícola, 5).

FERRARO, A. E. et al. Influência da polinização com variedades de laranja-doce sobre o número de sementes de tangelo Nova. Revista Brasileira de Fruticultura, Jaboticabal, v. 28, n. 2, p. 244-246, 2006.

FOOD AND AGRICULTURE ORGANIZATION (FAO). Food and agricultural commodities production. 2013. Disponível em: <http://faostat.fao.org/site/339/default. aspxr>. Acesso em: jan. 2013.

GAYET, J. P. Qualidade de frutas cítricas para exportação. Laranja, Cordeirópolis, v. 14, n. 1, p. 87-90, 1993.

GUARDIOLA, J. L. Frutificação e crescimento. In: SEMINÁRIO INTERNACIONAL DE CITROS, 2., 1992 , Bebedouro. Anais... Bebedouro: Fundação Cargil, 1992. p. 1-26.

MISCHAN, M. M.; SALIBE, A. A. Melhoramento do tangor Murcote: número de sementes e peso das frutas. In: JORNADA CIENTÍFICA DE BOTUCATU, 8., 1979, Botucatu. Anais... Botucatu: Unesp, 1979. p. 44.

OLIVEIRA, R. P. et al. Fisiologia da formação de sementes de citros. Pelotas: Embrapa Clima Temperado, 2004. (Documentos, 119).

PIO, R. M. et al. Variedades de copas de citros. In: MATTOS JÚNIOR, D. et al. (Eds.). Citros. Campinas: Instituto Agronômico/Fundag, 2005. p. 37-60.

PUCHADES, J. Influencia de la polinización en las características del fruto de cv. Fortune. 2002. 129 f. Trabajo Fin de Carrera - Escuela Universitaria de Ingeniería Agrícola, Universidad Politécnica de Valencia, Valencia, 2002.

SÓCIAS, R. La polinizacion de los frutales. Hojas Divulgadoras, Zaragoza, v. 17, n. 1, p. 3-18, 1987. 